\title{
ÉTICA DEMOSTRADA SEGÚN EL ORDEN GEOMÉTRICO, DE BARUj SPINOZA
}

\author{
ETHICS DEMONSTRATED IN GEOMETRICAL ORDER, \\ BY BARUCH SPINOZA
}

Federico Ocaña

DOI: 10.26754 /ojs_arif/arif.202024828

B. Spinoza (2020), Ética demostrada según el orden geométrico. Traducción y edición de Pedro Lomba. Madrid: Trotta.

La obra de Baruch o Baruj Spinoza sigue siendo objeto de interpretación y discusión. El magnetismo de su escritura y el de su vida corren parejos. Este se debe quizá a que Spinoza, sin encarnar en exclusiva el espíritu de su tiempo, sí estuvo entre quienes más lo sufrieron, gracias a un proceso de descrédito por el que pasaron Uriel da Costa o Juan de Prado, nombres que se deslizan en algunas de las notas que acompañan la introducción de la presente edición, preparada por Pedro Lomba y publicada en la colección Libros del Aire por Trotta, nombres que fueron reivindicados ya en 1987 en un estudio aún hoy central como La sinagoga vacía de Gabriel Albiac. Aquel proceso adelantó a su vez otros sufrimientos que vendrían, mayores y más perversos. Descalificaciones personales y filosóficas se sucedieron durante varios siglos y desembocaron en persecución laboral, académica, moral y racial contra pensadores que siguieron la estela de Spinoza en la comprensión del mundo como un complejo entramado arquitectónico de causas, una arquitectura no por compleja menos orgánica, es decir, libre del prejuicio antropomorfista que atribuye al mundo una estructura humana, en el sentido plural de la palabra (un mundo, por tanto, que ni es "de naturaleza humana", ni relativo a ella, ni "comprensivo, sensible" para con las pasiones o la fortuna de los hombres). Las causas de tal persecución pudieron ser diversas: bien por afirmar la necesidad de cuanto existe; bien por buscar una manera de hablar de Dios sin plegarse a la rutina de confesión alguna; bien por rescatar de la creación divina todo aquello considerado "imperfecto" e incluso por rescatar para la filosofía la tarea de explicar el error en las ideas, el papel de la imaginación y recuperar la 
centralidad del cuerpo; bien por negarse a seguir los pasos de Descartes en su separación de las sustancias infinita, extensa y pensante, y consecuentemente, por oponerse también a la reafirmación, más que demostración, de Dios rayana en el irracionalismo y, de nuevo, al ensoberbecimiento de la sustancia pensante, que se impone técnicamente sobre la extensa; bien por denunciar el riesgo ético y político de una interpretación de la libertad deudora o, como mínimo, solidaria con la noción católica de la gracia, que permite seguir afirmándola (a la libertad) incluso a pesar de la necesidad natural a que conduce el sistema cartesiano.

O quizá, dicho de otra forma, también se deba, aquel magnetismo, a que su Ética demostrada según el orden geométrico supone la cristalización y radicalización filosófica por antonomasia de algunos principios teóricos de la Modernidad, una propuesta con la que, de nuevo, se anticipó en varios siglos en sus principales postulados a algunos de los pensadores de mayor alcance e influencia de los siglos XIX y XX.

La producción de los últimos años permite comprobar la actualidad de las discusiones que inauguró: conviven en bibliotecas y librerías las ediciones de - $\mathrm{y}$ cito sólo aquellas en circulación comercial- Atilano Domínguez, Vidal Peña y Manuel Machado, que se habían enfrentado a la obra magna del autor de origen sefardí. La edición preparada por Lomba está llamada a convertirse en referente para cualquier lector inquieto de la obra de Spinoza y del canon filosófico de la Modernidad.

Esta edición, amén de las relevantes referencias que mencionábamos sobre la raíz heterodoxa del pensamiento de Spinoza, incluye una introducción que presenta y disputa el sentido del texto con ayuda de abundantes notas. Estas son autoría tanto del propio Lomba, como de los intérpretes y traductores de la primera edición holandesa (De Nagelate Schriften van B. d. S. Als Zekedunst, Staatkunde, Verbetering van't Verstand, Brieven en Antwoorten, de 1677), la cual, por cierto, se contrasta en varias ocasiones con la edición canónica de Gebhardt, por ejemplo, para señalar pasajes que los Nagelate Schriften omiten. Si en las notas al cuerpo del texto Lomba ofrece un panorama erudito sobre la biblioteca de Spinoza a través de citas implícitas (Terencio, Cicerón, Tácito, Góngora) y aclara el sentido de determinados términos de la traducción, permitiendo, gracias a la presencia del texto latino, confrontar su elección con el original, en la introducción recurre a citas de todos los tratados y la Correspondencia completa, dando cuenta de que parte de la potencia y el alcance de la Ética son anteriores incluso a su publicación, pues en esos escritos y en este intercambio epistolar se percibe un debate académico y personal que dejará huella en su redacción. 
Se presenta, además, una extensa bibliografía, dividida en "Ediciones y traducciones de la Ética", "Instrumentos de trabajo" y "Algunos estudios y comentarios", para ayudar al lector a entender la perspectiva polémica de la Ética y el enfoque del editor y preparador del texto. De la primera, a saber, la confrontación de Spinoza con el sistema de Descartes, hablaremos más adelante. En cuanto al segundo, el enfoque filosófico del editor, destacan los estudios de Pierre-François Moreau, autor asimismo de una edición de la Ética publicada en Francia también en la primavera de este 2020, Fokke Akkerman o, en cuanto a estudios transversales y que están a la base de la hermenéutica del texto y su contexto, Jean-Luc Marion y Carl Schmitt.

Para finalizar este pequeño recorrido por los aspectos técnicos de la edición, el libro que tratamos incorpora cuatro anexos: el primero, la "Denuncia de Niels Stensen de la filosofía de Spinoza al Santo Oficio", nos habla del rechazo de las posiciones de Spinoza por parte de alguien próximo al filósofo y de la rápida actuación de la ortodoxia católica; el segundo, "El vocabulario de los afectos", coteja la edición de Desmartes de Las pasiones del alma de Descartes con el francés original y con los términos latinos de Spinoza; el tercero, la "Biblioteca hispánica de Spinoza", un catálogo que sirve para ver en algunos de los títulos, en las palabras de esos autores, vocablos y, sobre todo, actitudes, que recogerá el propio Spinoza y que en esta edición española cobran más sentido que nunca, dado que el autor de la Ética domina el español y lo considera, como prueba la selección de textos, lengua de uso filosófico corriente; el cuarto anexo recoge y ordena las referencias internas.

Los anexos contribuyen, así, a desentrañar el texto en su sentido filológico e histórico más literal o cercano. En último lugar, destaquemos que la edición presenta el texto en latín y castellano, un lujo que desacostumbramos a disfrutar los lectores de filosofía en España — no así en Francia o Inglaterra, donde las ediciones bilingües son comunes incluso en ediciones de bolsillo-y, de paso, sitúa a Spinoza como un raro arquitecto de la Modernidad, porque, a fuerza de haber sido interpretado como un discípulo extravagante del lenguaje claro y distinto de Descartes, se ha olvidado que la potencia del texto, su explosividad, consiste en esbozar una Modernidad distinta, hasta cierto punto anti-moderna, si fuera posible tal antinomia, algo que solo se comprende adecuadamente atendiendo a los textos que median entre uno y otro autor — tal es el caso de la edición latina que hace Desmartes de Las pasiones del alma-.

Y es que la Modernidad hija de Descartes, que es con grandes matices nuestra Modernidad (piénsese en el trato que reciben uno y otro por parte de Kant, 
Hegel y las grandes escuelas de los siglos XIX y XX), ha elegido la libertad como estandarte, convirtiéndola en la palabra vacía predilecta para ser rellenada con uno u otro contenido por cualquiera, al socaire de sacerdotes y reyes, que vienen a ser lo mismo, como dirá Spinoza de un modo mucho más elegante en el Tratado Teológico-Politico.

La Ética opera, desde su estructura y su punto de partida, como un tratado, efectivamente, contra Descartes: si este fiaba la demostración de la existencia de Dios a un excedente de certeza, como una vía de escape a lo que de verdad le interesaba, a saber, el conocimiento humano, Spinoza invierte el orden y caracteriza la sustancia divina, situada para mayor énfasis al comienzo de su investigación, como la única infinita y eterna y por tanto la única sustancia como tal, de la que se derivarán sus infinitos atributos y sus modos. El vocabulario, inicialmente, sigue siendo heredero de Descartes, el momento histórico lo exige, pero la solución será radicalmente otra: no hay dos sustancias, sino una; el edificio de la filosofía no se ha de empezar por el conocimiento humano, sino por una definición precisa de la sustancia y en esa construcción Dios no puede quedar como un garante abstracto del acierto — matemático— de los hombres, sino como fundamento ontológico de las cosas. Ese, y no otro, es el papel de la divinidad y en esta concepción de la misma reside la radicalidad de Spinoza: "las cosas no han podido ser producidas por Dios de otro modo ni según otro orden que como han sido producidas" y "La potencia de Dios es su esencia misma" (E1p34). Dios no se entromete en la naturaleza, no hay lugar para el engaño o el milagro: ante nosotros, la naturaleza es ella misma despliegue de la omnipotencia de Dios.

La presentación destaca cómo en la medida en que Descartes había basado su avance, como decimos, epistemológico más que metafísico, en la nueva ciencia baconiana, en el rechazo de los sentidos y la apuesta por un método matemático de racionalidad, modelo algo confuso en un primer estadio, pues se entremezcla con la intuitus, más despejado a medida que se diferencia de la matemática vulgar y asciende a mathesis universalis, en esa medida, decimos, se había visto forzado a admitir el innatismo de las ideas (que Spinoza compartirá) pero, en otro orden, también una posición incómoda sobre el papel que debe jugar Dios en ese plano, como decimos, epistemológico. Ahí, Descartes fallaba al explicar la unión de alma y cuerpo y ofrecer a Dios como garante de la verdad. Spinoza parece abrir una brecha de sentido entre Dios y el género humano — recordemos también que pensamiento y extensión son sólo dos atributos más, los dos únicos que conocemos-, y parece que Descartes lo habría remendado trayendo a Dios desde el plano ontológico (las críticas de Spinoza sobre este punto sobre el que 
incidimos estallan en el Prefacio de la Parte quinta), pero lejos de ello, Spinoza ofrece, desde las proposiciones centrales E2p7, E2p8 y en adelante, una solución de encaje para Dios y los hombres: la verdad, dirá Spinoza, no puede depender de la voluntad infinita de Dios, separada de la materia y de carácter arbitrario, de la misma manera que el alma no puede estar vinculada al cuerpo por medio de espíritus sutilísimos en la glándula pineal sino que deben ser ya una y la misma cosa, contemplada desde el atributo del pensamiento y la extensión. El hiato de comunicación que se producía en Descartes entre sustancias, Spinoza lo resuelve apelando a la comunicación entre modos del mismo atributo. La causalidad en uno - pensamiento — no debe atribuirse a la otra — extensión—, y viceversa. Las cosas mismas y sus conexiones causales son ya, en definitiva, despliegue de la esencia y la potencia divinas.

La edición es particularmente meticulosa, fiel al texto latino e incorpora notas y variantes con rigor científico y valor cultural añadido. No aborda directamente las debilidades del sistema geométrico de la Ética ni impone una lectura dirigida sobre el texto en función de proposiciones concretas, como ofrecía por ejemplo Vidal Peña en un esfuerzo de comprensión que reconocemos notable, sino que opta por una traducción más literal en la que se filtran la potencia del pensamiento, las conexiones culturales y las referencias críticas que se materializan en una resignificación del léxico filosófico que socava ora la metodología de pensadores anteriores, ora las soluciones aportadas a los problemas centrales (la causalidad, la naturaleza del alma y su unión con el cuerpo, el estatuto ontológico y la verdad de las ideas, la dependencia de las pasiones y su difícil gobierno, la virtud y la libertad) que aún hoy nos ocupan.

Federico Ocaña

Universidad Complutense de Madrid fedeocan@ucm.es 